\title{
Interfacing neuroVIAS and NEST
}

\author{
Oliver Schmitt ${ }^{1 *}$, Peter Eipert ${ }^{1,2}$, Andreas Wree ${ }^{1}$, Klaus-Peter Schmitz ${ }^{2}$ \\ From Nineteenth Annual Computational Neuroscience Meeting: CNS*2010 \\ San Antonio, TX, USA. 24-30 July 2010
}

Our framework (neuroVIAS) integrates neuroimaging, brain-mapping, neuroanatomic ontologies and tracingbased connectivity data and allows to analyze these data in multiple modalities. Most of the data has been gathered from real brains, such as the information about connections between structures at different levels of resolution. These information include features like strength, inhibition or excitation. It is intended to use the collected data as an input for the simulation of neuronal networks with sophisticated simulation environments like NEST. As a starting point, a graphical user interface in neuroVIAS has been developed, that allows
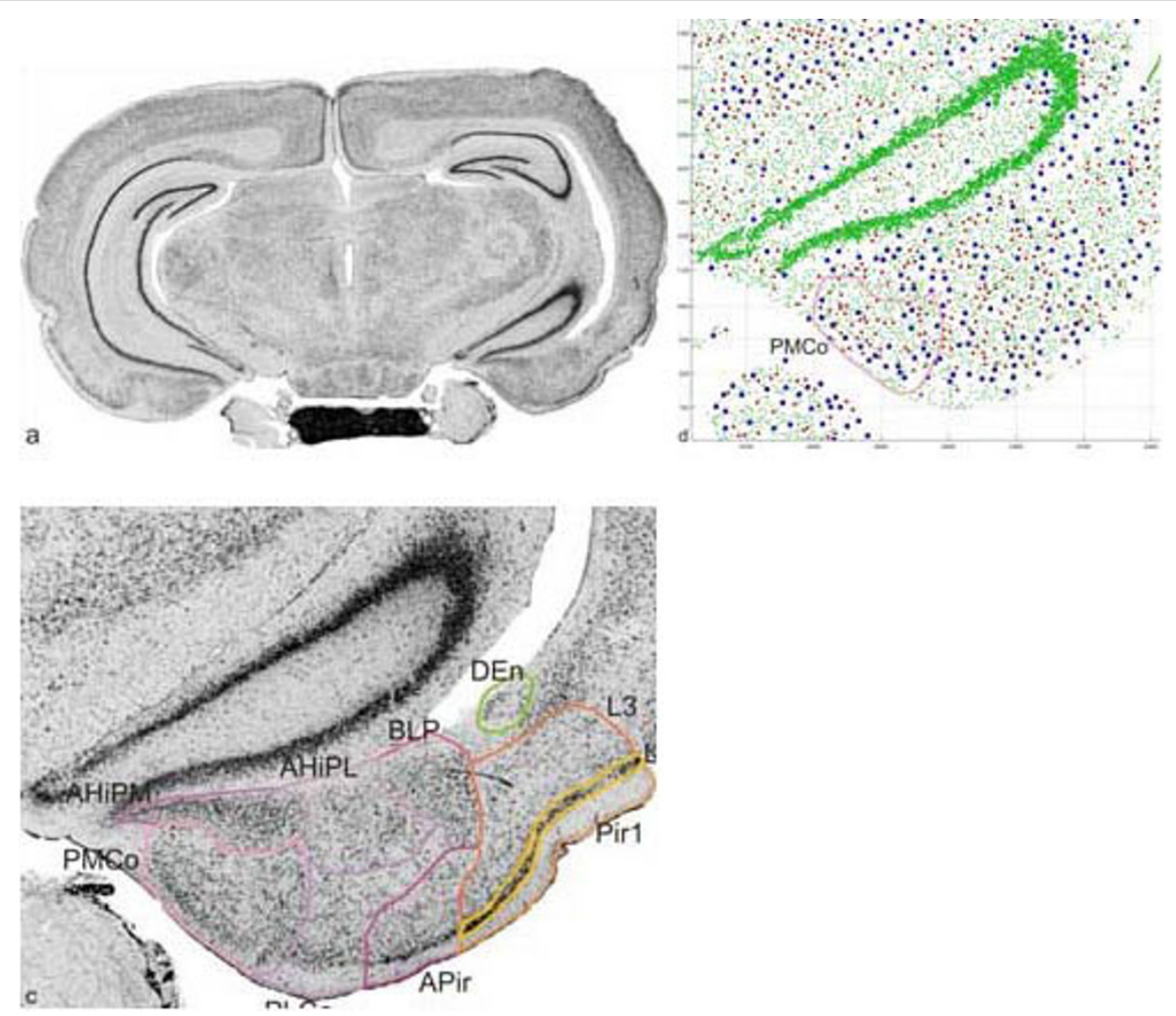

Figure 1 Overview of a rat brain section. The magnification shows the amygdala with annotations. Cell locations in the cell estimation are assigned to mapped brain regions.

\footnotetext{
* Correspondence: schmitt@med.uni-rostock.de

'Department of Anatomy, University of Rostock, Rostock, 18055, Germany 


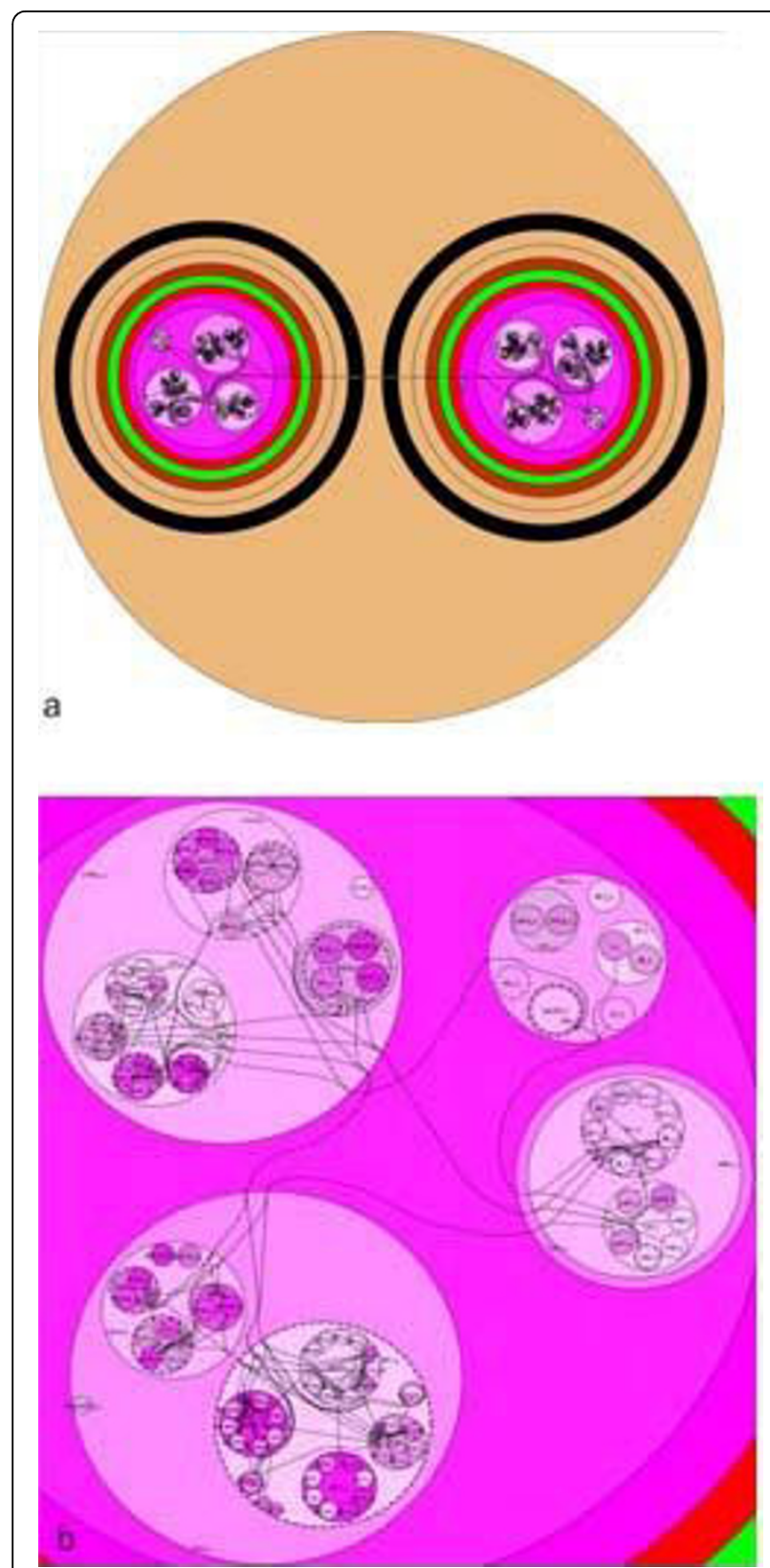

Figure 2 a) A hierarchy preserving connectivity visualization of the site-symmetric ontology. b) Magnification of the amygdala with edge bundled connectivities.

the specification of a simulation according to NEST guidelines based on filtering mechanisms of the rat connectome.

neuroVIAS is a platform independent JAVA application allowing the administration of multiple ontologies of different nervous systems. Neurohistological, stereotacticand image processing methods were used to obtain image data at high spatial resolution of a whole Wistar rat brain. Computer vision methods are used to obtain estimations of cells numbers in the mapped brain regions (Fig. 1). Additionally, 25000 connectivities were extracted from 420 tracing publications and imported in the neuroVIAS framework (Fig. 2). The 5000 neuroanatomic terms are organized hierarchically allowing the definition of scale dependent sets of brain regions for simulation. Additionally, attributes can be defined and assigned to the terms. Two types of attribute definitions are available: a hierarchical approach, where attributes can be organized in a hierarchy and a free configurable table method to define complex parameter sets. These parameters can be used for simulation studies. Using the spatial position of brain regions it is possible to compute distances in the neuronal network and including this information in the network simulation.

In this contribution we present the interface that allows the definition of parameters and adaption of new parameters for simulations in NEST. This open framework approach integrating relevant neuroimaging, mapping, ontology, connectivity data and different possibilities to administer brain region dependent sets of parameters for large scale simulations offers the opportunity to analyze dynamics of single regions and region ensembles of a realistic rat brain neuronal network.

\section{Author details}

'Department of Anatomy, University of Rostock, Rostock, 18055, Germany. ${ }^{2}$ Department of Implantation Technology and Biomaterials, University of Rostock, Rostock, 18119, Germany.

Published: 20 July 2010

doi:10.1186/1471-2202-11-S1-P135

Cite this article as: Schmitt et al:: Interfacing neuroVIAS and NEST. BMC Neuroscience 201011 (Suppl 1):P135.

\section{Submit your next manuscript to BioMed Central} and take full advantage of:

- Convenient online submission

- Thorough peer review

- No space constraints or color figure charges

- Immediate publication on acceptance

- Inclusion in PubMed, CAS, Scopus and Google Scholar

- Research which is freely available for redistribution 